This manuscript version is made available under the CC-BY-NC-ND 4.0

1icense http://creativecommons.org/1icenses/by-nc-nd/4.0/

\title{
1 Determining optimum rejuvenator addition location in asphalt 2 production plant
}

3 Martins Zaumanis ${ }^{a}$ (corresponding author), Lukas Boesiger ${ }^{\mathrm{b}}$, Bernhard Kunz ${ }^{\mathrm{c}}$, Maria

4 Chiara Cavalli ${ }^{\text {, }}$ Lily Poulikakos ${ }^{\mathrm{e}}$

5 a EMPA, Swiss Federal Laboratories for Materials Science and Technology, Überlandstrasse 129, CH-Dübendorf, Switzerland, 6 martins.zaumanis@empa.ch, +41587656075

7 b Ammann Schweiz AG, Eisenbahnstrasse 25, CH-4901 Langenthal, Switzerland, lukas.boesiger@ammann-group.com

$8 \quad{ }^{\mathrm{c}}$ BHZ Baustoff Verwaltungs AG, Eggbühlstrasse 36, CH-8050 Zürich, Switzerland, b.kunz@bhz-zh.ch

9 d EMPA, Swiss Federal Laboratories for Materials Science and Technology, Überlandstrasse 129, CH-Dübendorf, Switzerland, 10 mariachiara.cavalli@empa.ch

$11{ }^{\mathrm{e}}$ EMPA, Swiss Federal Laboratories for Materials Science and Technology, Überlandstrasse 129, CH-Dübendorf, Switzerland, 12 lily.poulikakos@empa.ch

14 Abstract

15 Rejuvenator is an oil that can be added during asphalt production to restore Reclaimed Asphalt

16 Pavement (RAP) binder. Ten potential locations for rejuvenator addition in asphalt plant were

17 ranked in terms of pavement performance, plant operation, and environmental safety. A full scale

18 production was performed to compare rejuvenator addition to cold RAP on conveyor belt versus

19 addition to hot RAP in mixer (video https://youtu.be/LYBq93e8BG0). Mixture test results

20 indicated that spraying of rejuvenator onto cold RAP facilitates rejuvenator diffusion in RAP

21 binder resulting in improved asphalt fatigue and crack propagation resistance. Both addition

22 locations generated equal organic carbon emissions from asphalt plant.

23 Key words: asphalt recycling; RAP; rejuvenators; emissions; environment; production; partial

24 blending; black rock; pavement; road

25 Declarations of interest: none

\section{Highlights}

27 - Rejuvenator addition on RAP conveyor belt, dryer outlet or in mixer is recommended

28 - Early rejuvenator addition might be advantageous for mixture performance

$29-$ Rejuvenator addition before and after RAP dryer produce the same emissions 


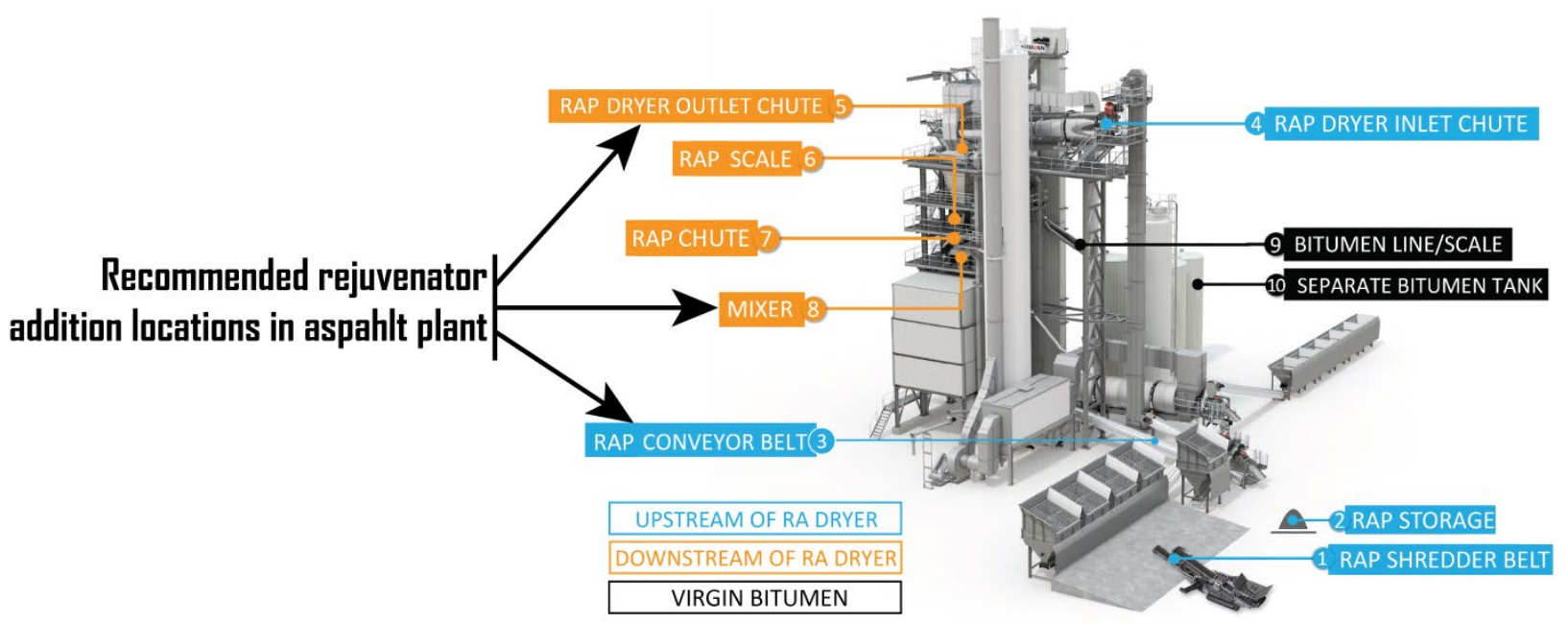

\section{Introduction}

The use of Reclaimed Asphalt Pavement (RAP) in production of new hot mixtures is continuing

to increase because of economic and environmental benefits. However, the increase in RAP use to a large extent owes to the fact that producers are choosing to put low RAP rates in more mixtures and to a lesser extent to increased RAP rate in a given mix design. To further raise the

8 re-use of reclaimed asphalt, a higher RAP rate needs to be used in mixtures. This can only be achieved by rejuvenating the aged asphalt binder film. Use of softer binder grade has historically

10 been the most popular approach, but it has several drawbacks: (1) at high RAP rate the effect of

11 using softer bitumen becomes less evident [1,2] and (2) changing between the RAP sources and

12 using various RAP rates in mix design would mean that multiple soft binder grades (and

13 corresponding number of bitumen tanks) are necessary. This is difficult to ensure.

14 Rejuvenators are oils that are aimed at restoring the mechanical performance of the RAP for

15 another asphalt pavement service period. Contrary to when softer binders are used, they provide

16 flexibility to switch between different types and contents of RAP and can rejuvenate binder at up

17 to $100 \%$ RAP content [3-5]. Their use, however, also imposes new challenges. Control of RAP 
1 homogeneity, ensuring optimum rejuvenator dosage, homogeneous distribution of rejuvenator,

2 good diffusion of rejuvenator into the RAP binder film, and good blending of virgin with RAP

3 binder are five key parameters for ensuring the expected pavement performance. Only two of the

4 five parameters, control of RAP homogeneity and determination of optimum rejuvenator dose,

5 partially depend on the work in the mix design laboratory. At the same time all five depend on

6 the practices in asphalt plant and cannot be accurately reproduced in laboratory. Diffusion of

7 rejuvenator into RAP binder film is of particular importance because this "activates" the RAP

8 binder and makes it available for blending with virgin materials to form a homogeneous binder

9 film on RAP and virgin aggregates. It is, however, recognized that not all of RAP binder is

10 activated and part of it behaves as "black rock" thus reducing the effective binder content in the

11 mixture [6,7]. This in turn can lead to low temperature and fatigue cracking: risks that are

12 already associated with the use of RAP due to its high stiffness. Many researchers have proposed

13 methods to determine the proportion of "active" RAP binder [8-10]. However, virtually no

14 studies have focused on practical means for increasing the RAP binder activation. A preliminary

15 work by the authors [11] evaluated effect of rejuvenator addition location in asphalt plant on the

16 properties of extracted binder and the results demonstrated that rejuvenator effectiveness for

17 binder rejuvenation is not lost regardless of its addition location. However, the standard binder

18 extraction procedure inherently blends rejuvenator and all of RAP binder together thus

19 evaluation of rejuvenator diffusion is not possible.

20 This research then aims to evaluate means for maximizing the "active" RAP binder by

21 comparing various locations for rejuvenator addition in asphalt plant. The different options are

22 compared with respect to pavement quality, efficiency of rejuvenator addition (homogeneous

23 distribution, residence time, diffusion, loss of rejuvenator), process stability, practicality, 
1 environmental effects (emissions, leaching), operator and plant safety. A summary of the study

2 can be viewed in Video 1.

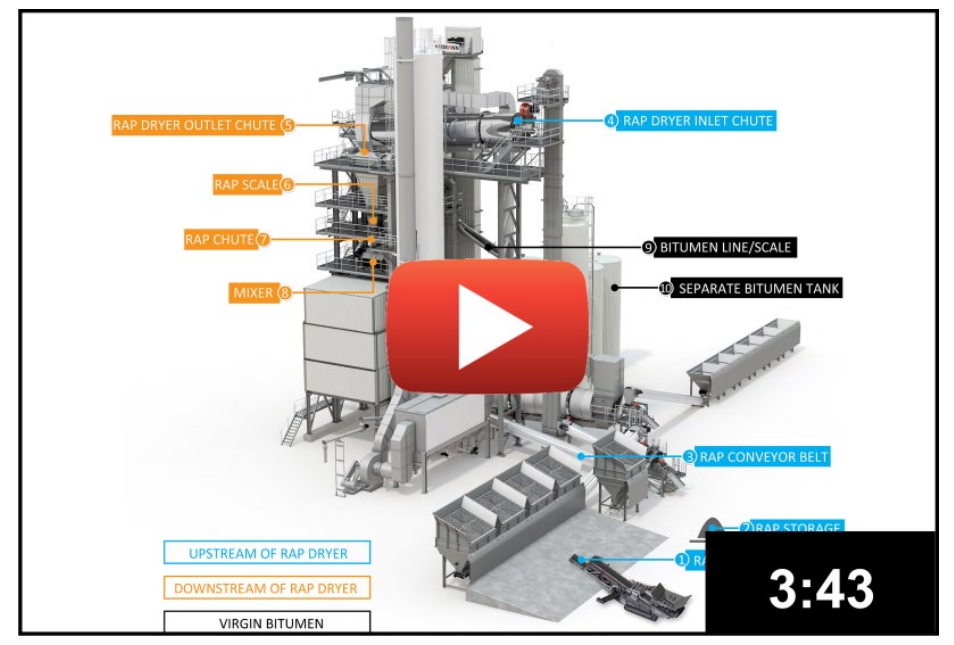

Video 1: Research summary (https://youtu.be/LYBq93e8BG0)

\section{$5 \quad 1.1$ Disclaimer}

6 The study will consider only batch asphalt plant types, but at the same time similar analysis can

7 be applied to analysis of continuous type asphalt plants. For all reasoning it is assumed that

8 liquid non-flammable rejuvenators are considered. If other conditions are used, then a thorough

9 evaluation, including a risk assessment and hazard identification according to European ATEX

10 directives: (1) equipment directive 2014/34/EU and (2) user/workplace directive 1999/92/EC,

11 and/or locally applicable standards must be carried out.

\section{1.2. Objective}

13 The objective of the study is to compare different locations for rejuvenator addition in a batch

14 asphalt plant and offer recommendation for optimum location based on analytical assessment and

15 full-scale production test results. 


\section{2. Materials and methods}

\section{$2 \quad 2.1$ Analytical comparison of rejuvenator addition points}

3 An analytical analysis of a batch asphalt plant was carried out to identify potential rejuvenator

4 addition locations. This was performed by listing benefits and drawbacks for each of the

5 locations in terms of environmental aspects, operator and plant safety, pavement quality,

6 technological process and economic reasons. The goal of this analysis was to identify the most

7 promising locations for evaluation in a practical full-scale experiment.

\subsection{Materials}

9 After analytical comparison, two rejuvenator addition locations were selected for comparison in

10 a full scale experiment. Only RAP and rejuvenator were used for evaluation of mixture

11 properties without any other virgin materials. Such approach was chosen to minimize the number

12 of variables and achieve the objective of the study.

13 RAP with maximum aggregate size of $22 \mathrm{~mm}$ (Table 1) was characterized before production. It

14 had a binder content of $3.9 \%$ and penetration of $200.1 \mathrm{~mm}$.

15 Table 1. Particle size distribution of RAP

\begin{tabular}{|c|c|c|c|c|c|c|c|c|c|c|c|c|}
\hline Sieve, mm & 0.063 & 0.125 & 0.250 & 0.500 & 1.0 & 2.0 & 4.0 & 5.6 & 8.0 & 11.2 & 16.0 & 22.4 \\
\hline $\begin{array}{l}\text { Amount } \\
\text { passing, \% }\end{array}$ & 7.40 & 11.70 & 19.20 & 27.70 & 35.90 & 48.30 & 62.90 & 71.30 & 82.50 & 90.20 & 97.10 & 100.00 \\
\hline
\end{tabular}

17 A rejuvenator based on distilled tall oil was used in the experiment. It is a byproduct of Kraft

18 manufacturing process. The additive is classified as non-hazardous and has a flash point above

$19280^{\circ} \mathrm{C}$ making it safe for use in the RAP dryer. Viscosity at $20^{\circ} \mathrm{C}$ is $100 \mathrm{~mm}^{2} / \mathrm{s}$ thus liquid

20 additive dosing systems can be used. Based on earlier experience of the authors, $5 \%$ rejuvenator

21 content from binder mass was chosen for the experiment [12]. 


\section{$1 \quad 2.3$ Production plant}

2 Rejuvenator diffusion depends on plant parameters, most notably residence time on RAP binder

3 and temperature. For this reason description of the conditions in the production plant is provided.

4 Ammann "Uniglobe 200" plant with "RAH 100" RAP dryer was used for the production. It was

5 described by Zaumanis et al. [13]. The RAP heating and drying system has two stages: a static

6 combustion chamber and a rotating RAP dryer where hot air is circulated. The static combustion

7 chamber has a diameter of approx. 2.5 meters and a length of approx. 5 meters and is equipped

8 with a 14 MW dual fuel burner (natural gas or heating oil "EL"). The rotating RAP dryer has a

9 diameter of approx. 2.5 meters and a length of approx. 7 meters; it has a maximum RAP

10 throughput capacity of approximately $160 \mathrm{t} / \mathrm{h}$. The RAP material residence time in the RAP

11 dryer is from one up to several minutes depending on RAP material, RAP feed rate, RAP

12 moisture and dryer revolutions (can be varied according to requirements). This indirect heating

13 principle allows heating RAP without direct contact with the flame, to a conventional hot-mix

14 asphalt production temperature of $160^{\circ} \mathrm{C}$ (used in this experiment). The RAP dryer is located on

15 a tower to ensure gravity-driven material discharge to the storage unit and mixer.

16 Exhaust gases from either the virgin aggregate (VA) dryer and/or the RAP dryer are combined

17 upstream of bag filter. In the bag filter, the exhaust gas is cleaned from coarse and fine dust

18 before it is released to the atmosphere through the plant's exhaust gas chimney.

\section{$19 \quad 2.4$ Binder tests}

20 The RAP binder was extracted according to EN 12697-1 using toluene and recovered according

21 to EN 12697-3. Penetration was determined according to EN 1426. 


\subsection{Mixture tests}

2 The focus of the study is on mixture tests that would allow highlight the differences in

3 rejuvenator effectiveness depending on its addition location. Two criteria were used to select the

4 particular test methods used in the experiment: (1) testing of properties that are traditionally

5 considered unfavorable for high RAP mixtures - fatigue and cracking and (2) sensitivity of the

6 test method to binder content and stiffness allowing to capture the effects of binder activation.

7 Stiffness, fatigue and Semi-Circular Bend (SCB) test fulfil these requirements and were therefore

8 used in this study. These tests were used as indicators of rejuvenator effectiveness at each

9 addition location and not for prediction of the long-term cracking performance. Long-term

10 performance evaluation would require aging of the mixtures but was not in the scope of this

11 paper.

12 In order to highlight the differences between the rejuvenator addition locations, every effort was

13 made to minimize rejuvenator diffusion after production. This was done for two reasons:

14 1) It was important to keep the conditions the same for all the samples because for practical

15 purposes it is not possible to produce and test all the samples simultaneously. The

16 diffusion that occurs while some samples are sitting in laboratory while other are being

17 tested would jeopardize this objective.

18 2) Although it is true that the rejuvenator diffusion will continue during the service life of

19 the pavement, it must be ensured that the pavement has the required properties already

20 when it is opened to the traffic. It is possible that the asphalt plant is at an immediate

21 vicinity of the paving site and thus rejuvenator diffusion between the production and

22 opening to the traffic is relatively short. For this reason no aging was performed on the

23 asphalt samples. 
1 In order to minimize the rejuvenator diffusion that is not related to the production process,

2 following collection of asphalt samples from the asphalt plant, they were kept in an

3 environmental chamber at $+4^{\circ} \mathrm{C}$ until ready for heating and compaction. To keep the sample

4 preparation time short, the mixture was pre-heated in a microwave oven for 10 minutes followed

5 by heating in an oven at $150^{\circ} \mathrm{C}$ for $1 \mathrm{~h}$ until a homogeneous temperature was reached throughout

6 the mixture. The total time that the samples were exposed to high temperature, including

7 production, sampling, re-heating in laboratory and compaction, was about two hours. This is

8 approximately similar time to a real-world situation when the jobsite would be near to the asphalt

9 plant.

10 Mixture samples were prepared using gyratory compactor with $150 \mathrm{~mm}$ diameter molds

11 according to EN12697-31 by targeting 4\% air voids. The samples were then cut to the required

12 height but no closer than $15 \mathrm{~mm}$ from the surface to avoid inhomogeneity. After determining

13 volumetric properties, the prepared samples were again placed into the environmental chamber at

$14+4^{\circ} \mathrm{C}$ until ready for conditioning and testing.

\section{$15 \quad 2.6$ Stiffness and fatigue}

16 Stiffness (EN 12697-26) followed by fatigue test (EN 12697-24) on the same specimens was

17 performed using dynamic indirect tensile test on cylindrical shaped specimens of $60 \mathrm{~mm}$ in height

18 and $150 \mathrm{~mm}$ in diameter. Stiffness tests were performed by applying a sinusoidal load at

19 frequencies of $0.1,1$ and $10 \mathrm{~Hz}$ at temperatures of $-10,10$ and $20^{\circ} \mathrm{C}$. The load level at each

20 frequency and temperature was chosen to induce horizontal strains in the specimen in the range

21 between 0.05 and $0.10 \%$. Four specimens were tested at each temperature and frequency. These

22 results were then used to create master-curves using the principle of time-temperature

23 superposition to shift data at multiple temperatures and frequencies to a reference temperature. 
1 This allows to view the stiffness data without temperature as a variable. A sigmoidal model was

2 used [14], with the shift factors calculated following the Williams-Landel-Ferry [15] relation:

$3 \log _{\mathrm{aT}}=\left(-\mathrm{C}_{1}\left(\mathrm{~T}-\mathrm{T}_{\mathrm{ref}}\right)\right) /\left(\mathrm{C}_{2}+\left(\mathrm{T}-\mathrm{T}_{\mathrm{ref}}\right)\right)$, where $\mathrm{a}_{\mathrm{T}}$ is a factor for shifting complex modulus at certain

4 temperature $\mathrm{T}$ to a reference temperature $\mathrm{T}_{\text {ref }}\left(20^{\circ} \mathrm{C}\right.$ in this study); $\mathrm{C} 1$ and $\mathrm{C} 2$ are material

5 constants obtained by least squares regression.

6 Fatigue test was performed at $10^{\circ} \mathrm{C}$ by applying a sinusoidal repeated loading at $10 \mathrm{~Hz}$ frequency.

7 Failure criterion $\left(\mathrm{N}_{\mathrm{f} / 50}\right)$ of $50 \%$ loss of initial stiffness modulus was used. Strain levels were

8 chosen to induce failure of the specimens at three distinct levels $\left(\sim 10^{5}, \sim 10^{5.5}, \sim 10^{6}\right)$. This allows

9 calculating another failure criterion - the strain at 1 million cycles $\left(\varepsilon_{6}\right)$.

\section{$10 \quad 2.7$ Crack propagation}

11 Semi Circular Bend (SCB) test at $25^{\circ} \mathrm{C}$ was used to determine crack propagation. According to

12 the experience of the authors and literature $[16,17]$ the SCB test at $25^{\circ} \mathrm{C}$ is highly sensitive to

13 RAP proportion, binder grade and binder content while according to the experience of the

14 authors, when performing it at $0^{\circ} \mathrm{C}$ (according to $\mathrm{EN} 12697-44$ ) the test is not sensitive to the

15 binder content or viscosity [18]. These are the properties that are important to evaluate the RAP

16 binder "activation" in this research. To prepare an SCB sample the 150mm diameter gyratory

17 samples were trimmed to $50 \mathrm{~mm}$ in height and cut in half. A notch of $15 \mathrm{~mm}$ in length and $3.5 \mathrm{~mm}$

18 in width was then sawed in the horizontal part to control crack initiation. Four samples per mix

19 were tested. During testing the specimen was positioned in three point testing frame and a load

20 was applied at a monotonic rate of $50 \mathrm{~mm} / \mathrm{min}$ along the vertical axes. Load and frame

21 displacement were measured during the test.

22 Results were expressed in terms of the Flexibility Index (FI) calculated according to AASHTO

23 TP 124-16. A typical test result is illustrated in Figure 1. First, fracture energy was calculated: 
$1 \mathrm{G}_{\mathrm{f}}=\mathrm{W}_{\mathrm{f}} /$ Arealig $\times 10^{6}$, where $\mathrm{G}_{\mathrm{f}}$ is fracture energy in $\mathrm{N} / \mathrm{m}, \mathrm{W}_{\mathrm{f}}$ is work of fracture (the area under

2 the load versus displacement curve) in Joules, Arealig is ligament length in $\mathrm{mm}^{2}$ multiplied by t,

3 and $\mathrm{t}$ is specimen thickness in $\mathrm{mm}$. FI was then calculated: $\mathrm{FI}=\mathrm{G}_{\mathrm{f}} /|\mathrm{m}| \times \mathrm{A}$, where FI is flexibility

4 index, $m$ is the post peak slope at the inflection point of the load-displacement curve in $\mathrm{kN} / \mathrm{mm}$,

5 and $\mathrm{A}$ is 0.01 .

6

10 Plant exhaust gas emission measurements were carried out with two instruments:

11 - Multi Gas Analyzer (MGA) "MRU MGA5" was used for measuring various gas

12 components, including exhaust gas temperature $\left(\mathrm{T}_{\mathrm{gas}}\right)$.

13 - Flame Ionization Detector (FID) "SICK FID 3006" was used for measuring Total Organic

14 Carbon (TOC), or Volatile Organic Compounds counted on carbon atoms (VOC- $\mathrm{C}_{1}$ ). 
1 The sensors of both emissions testing instruments were installed in the clean gas stack

2 downstream of the plant's main bag filter and upstream of the exhaust gas chimney as illustrated

3 in Figure 2. Since only concentration measurements and no air flow measurements were carried

4 out, the sensors were placed in the inlet duct to the chimney, downstream of the main blower. All

5 emission data was recorded with a mobile NI (National Instruments) LabVIEW SignalExpress

6 data acquisition system using a sampling rate of 1 data point per second for each signal $\left(\mathrm{s}^{-1}\right)$.

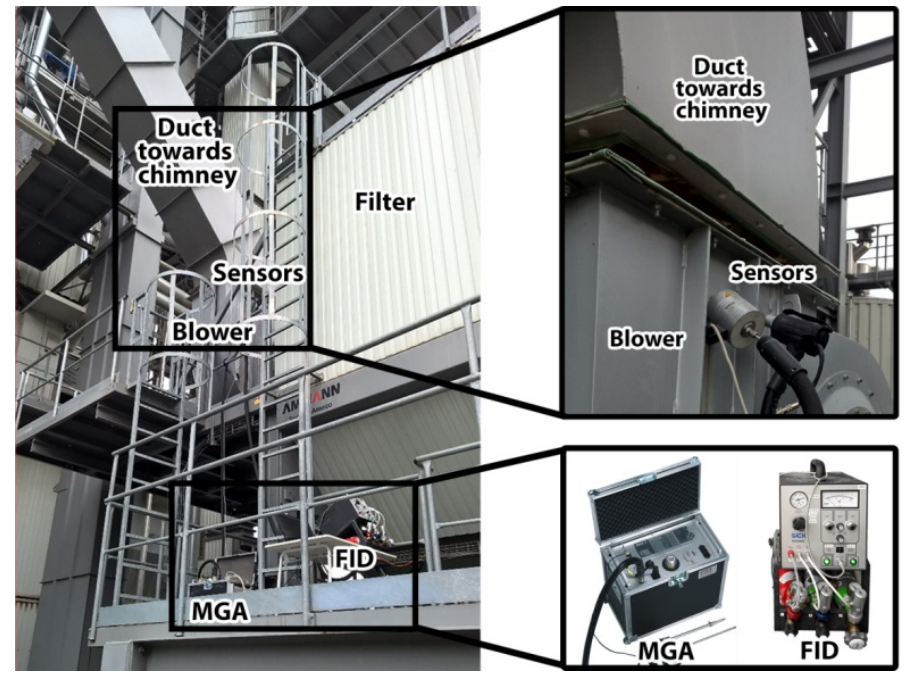

Figure 2. Location and positioning of MGA and FID emission testing instruments / sensors and emission data recording hardware

\section{Analytical comparison of rejuvenator addition locations}

The potential rejuvenator addition locations in asphalt plant can be categorized in three groups:

1. Upstream of RAP dryer drum

2. Downstream of RAP dryer drum

4 3. Bitumen

Within each of these groups there are several options resulting in at least ten potential locations

6 for rejuvenation addition as summarized in Figure 3. The factors that have to be taken into 
1 account when choosing the optimum location include environmental aspects (emissions, leaching

2 or rejuvenators into the ground), operator and plant safety, pavement quality (even rejuvenator

3 distribution, residence time, temperature, diffusion, loss of rejuvenator), technological (process

4 stability, practicability) and economic reasons. Based on Boesiger et al. [19] a summary of

5 benefits and drawbacks for each addition location is provided in Table 2. The number of each

6 addition location in Table 2 corresponds to the visualization in Figure 3. It must be noted that

7 these are analytical considerations based on the authors' experience and can change depending

8 on plant type, setup and experience of operation.

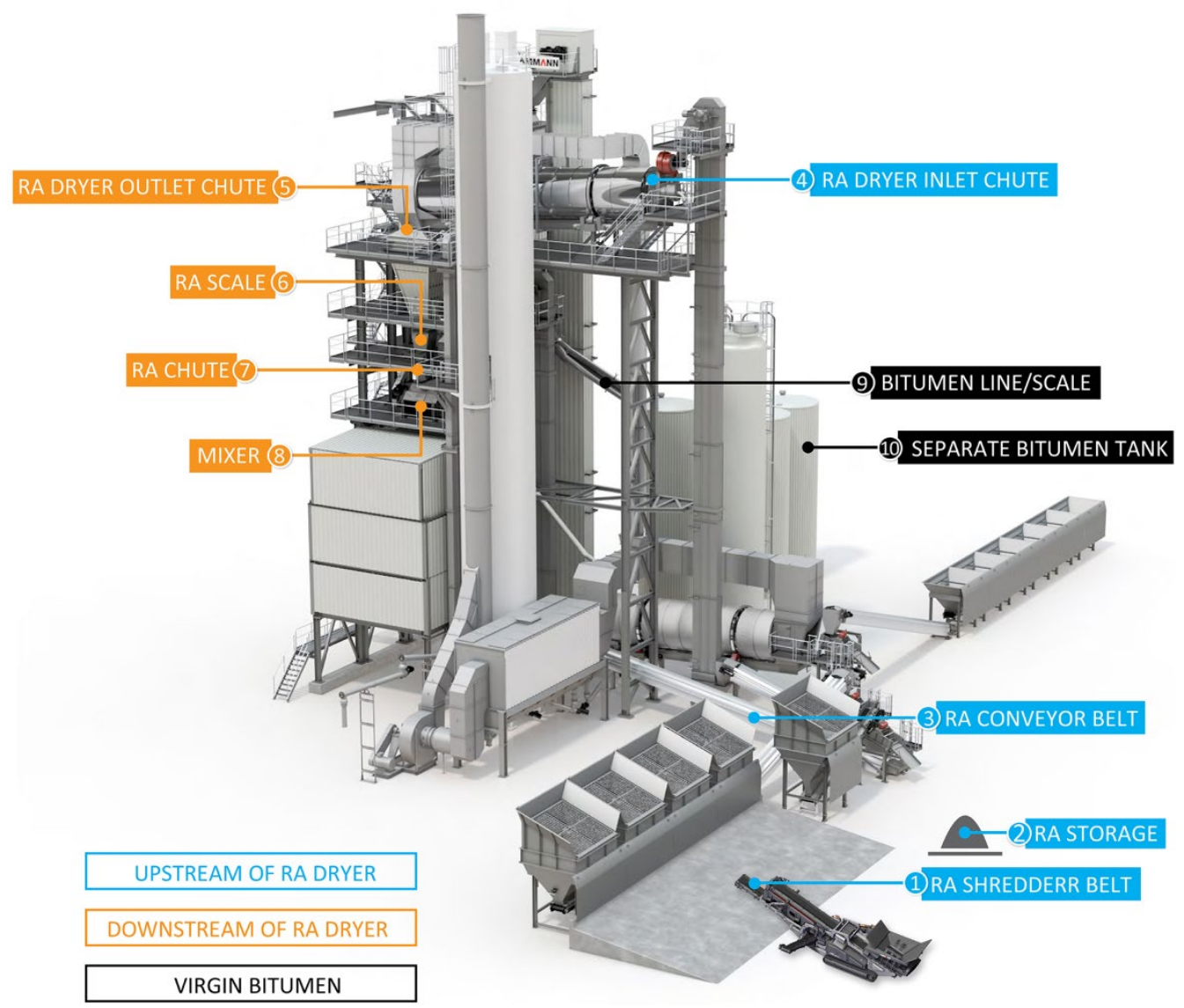

Figure 3. Rejuvenator addition locations (Source: Ammann) 


\begin{tabular}{|c|c|c|}
\hline $\begin{array}{l}\text { Addition } \\
\text { location }\end{array}$ & Benefit & Drawback \\
\hline \multicolumn{3}{|c|}{ Upstream of RAP dryer } \\
\hline $\begin{array}{l}\text { 1. RAP } \\
\text { shredder belt }\end{array}$ & $\begin{array}{l}\text { Long rejuvenator exposure on RAP binder } \\
\text { Potentially lower RAP heating temperature } \\
\text { due to lower RAP binder viscosity (reduced } \\
\text { emissions, energy consumption, increased } \\
\text { plant capacity) }\end{array}$ & $\begin{array}{l}\text { Inhomogeneous rejuvenator distribution } \\
\text { Rejuvenator drainage } \\
\text { Stockpile stickiness } \\
\text { Potential worker exposure to rejuvenator } \\
\text { Rejuvenator evaporation in RAP dryer } \\
\text { Possibly increased exhaust gas emissions due to } \\
\text { rejuvenator presence }\end{array}$ \\
\hline 2. RAP storage & $\begin{array}{l}\text { Long rejuvenator exposure on RAP binder } \\
\text { Potentially lower RAP heating temperature } \\
\text { due to lower RAP binder viscosity (reduced } \\
\text { emissions, energy consumption, increased } \\
\text { plant capacity) }\end{array}$ & $\begin{array}{l}\text { Inhomogeneous rejuvenator distribution } \\
\text { Rejuvenator drainage } \\
\text { Stockpile stickiness } \\
\text { Potential worker exposure to rejuvenator } \\
\text { Rejuvenator evaporation in RAP dryer } \\
\text { Possibly increased exhaust gas emissions due to } \\
\text { rejuvenator presence }\end{array}$ \\
\hline $\begin{array}{l}\text { 3. RAP } \\
\text { conveyor belt }\end{array}$ & $\begin{array}{l}\text { Long rejuvenator exposure on RAP binder } \\
\text { Potentially lower RAP heating temperature } \\
\text { due to lower RAP binder viscosity (reduced } \\
\text { emissions, energy consumption, increased } \\
\text { plant capacity) } \\
\text { Precise dosage based on RAP feed rate } \\
\end{array}$ & $\begin{array}{l}\text { Possibly inhomogeneous rejuvenator distribution } \\
\text { Potential worker exposure to rejuvenator } \\
\text { Rejuvenator evaporation in RAP dryer } \\
\text { Possibly increased exhaust gas emissions due to } \\
\text { rejuvenator presence }\end{array}$ \\
\hline $\begin{array}{l}\text { 4. RAP dryer } \\
\text { inlet chute }\end{array}$ & $\begin{array}{l}\text { Long rejuvenator exposure on RAP binder } \\
\text { Potentially lower RAP heating temperature } \\
\text { (reduced emissions, energy consumption, } \\
\text { increased plant capacity) } \\
\text { Precise dosage based on RAP feed rate }\end{array}$ & $\begin{array}{l}\text { Possibly inhomogeneous rejuvenator distribution } \\
\text { Potential worker exposure to rejuvenator } \\
\text { Rejuvenator evaporation in RAP dryer } \\
\text { Very short interaction of rejuvenator and binder } \\
\text { before heating likely resulting in high volatilization } \\
\text { of rejuvenator and increased exhaust gas emissions } \\
\text { due to rejuvenator presence }\end{array}$ \\
\hline \multicolumn{3}{|c|}{ Downstream of RAP dryer } \\
\hline $\begin{array}{l}\text { 5. RAP dryer } \\
\text { outlet chute }\end{array}$ & $\begin{array}{l}\text { Precise dosage based on RAP feed rate } \\
\text { Rejuvenator not exposed to RAP dryer } \\
\text { (potentially lower emissions, safety) }\end{array}$ & $\begin{array}{l}\text { Shorter exposure time compared to "upstream of } \\
\text { RAP dryer" options } \\
\text { Possibly inhomogeneous rejuvenator distribution }\end{array}$ \\
\hline 6. RAP scale & $\begin{array}{l}\text { Rejuvenator not exposed to RAP dryer } \\
\text { (potentially lower emissions, safety) }\end{array}$ & $\begin{array}{l}\text { Shorter exposure time to RAP binder compared to } \\
\text { "upstream of RAP dryer" options } \\
\text { Inhomogeneous rejuvenator distribution }\end{array}$ \\
\hline 7. RAP chute & $\begin{array}{l}\text { Rejuvenator not exposed to RAP dryer } \\
\text { (potentially lower emissions, safety) }\end{array}$ & $\begin{array}{l}\text { Shorter exposure time to RAP binder compared to } \\
\text { "upstream of RAP dryer" options } \\
\text { Inhomogeneous rejuvenator distribution }\end{array}$ \\
\hline 8. Mixer & $\begin{array}{l}\text { Rejuvenator not exposed to RAP dryer } \\
\text { (potentially lower emissions, safety) } \\
\text { Simple plant integration } \\
\text { Most precise rejuvenator dosing } \\
\text { Most homogeneous rejuvenator distribution }\end{array}$ & $\begin{array}{l}\text { Shorter exposure time compared to "upstream of } \\
\text { RAP dryer" options } \\
\text { Shortest rejuvenator exposure time to RAP binder }\end{array}$ \\
\hline \multicolumn{3}{|l|}{ Fresh bitumen } \\
\hline $\begin{array}{l}\text { 9. Bitumen } \\
\text { line/scale }\end{array}$ & $\begin{array}{l}\text { Precise rejuvenator dosing } \\
\text { Simple plant integration }\end{array}$ & No direct contact of rejuvenator with RAP binder \\
\hline $\begin{array}{l}\text { 10. Separate } \\
\text { bitumen tank }\end{array}$ & Precise rejuvenator dosing & $\begin{array}{l}\text { No direct contact of rejuvenator with RAP binder } \\
\text { No flexibility to change rejuvenators/dosages } \\
\text { depending on RAP rate and properties } \\
\text { Separate bitumen tank necessary }\end{array}$ \\
\hline
\end{tabular}


1 In order to compare the different options for rejuvenator addition some parameters in Table 2

2 should be given a priority over others:

1) The rejuvenator application should be safe for the environment and workers. Depending on the type of rejuvenator used this could filter out options No. 1 (RAP shredder belt), No. 2 (RAP storage) and No. 4 (RAP dryer inlet chute).

2) Direct contact of rejuvenator and RAP binder is preferred rather than pre-blending of rejuvenator with bitumen. This allows rejuvenator diffusion into RAP binder to soften it and maximize blending with virgin bitumen and aggregates. This preference screens out options No. 9 (bitumen line/scale) and No. 10 (separate bitumen tank).

3) Finally, precise rejuvenator dosage control and homogeneous distribution of rejuvenator on RAP binder are necessary for ensuring best pavement performance. These requirements screen out options No. 6 (RAP scale) and No. 7 (RAP chute) as well as the options deemed unacceptable previously (No. 1 and No. 2).

Finally three options of rejuvenator addition remain: No. 3 (RAP conveyor belt), No. 5 (RAP dryer outlet chute), and No. 8 (mixer). Addition location No. 3 is located upstream of RAP dryer and locations No. 5 and No. 8 are located downstream of RAP dryer. These three locations require further analysis.

\subsection{Rejuvenator addition at the RAP conveyor belt (No. 3)}

Rejuvenator is sprayed by means of nozzles installed on top of the belt, directly onto the RAP that is being transported by the conveyor belt from RAP cold feeders towards the RAP dryer. The rejuvenator dosage rate can be adjusted by the RAP feed rate or mass (if a scale is installed on the belt). Covering of the RAP belt to protect from wind and rain might be necessary to limit rejuvenator loss and operator health and safety hazards. 
2 Addition of rejuvenator upstream of the dryer allows longer contact time with RAP binder thus

3 increasing diffusion and consecutive RAP binder activation. This can be beneficial for ensuring

4 more transfer of RAP binder between RAP and virgin aggregates to ensure homogeneous binder

5 film thickness. The additional time (compared to addition in mixer) for which rejuvenator

6 interacts with RAP bitumen can be important to increase the mobilization of RAP binder.

7 Another potential benefit is that the viscosity of the hard RAP binder is reduced before heating in

8 RAP dryer thus enabling lower heating temperatures. This is important mainly because at high

9 RAP rate, emissions caused by heating of RAP are a dominant problem and even a small

10 reduction in heating temperature can reduce the magnitude of these emissions. Additionally, this

11 would reduce energy consumption and increase plant capacity.

12 3.1.2 Drawbacks

13 Since the RAP has to pass through the heating RAP dryer, only a rejuvenator with a high ignition

14 point can be used. The specific minimum ignition temperature depends on the plant type. Even if

15 not ignited, high temperature might cause chemical changes in rejuvenator composition. Another

16 potential problem is loss of volatile fractions inside the hot RAP dryer and a consecutive increase

17 in emissions and a reduction in rejuvenation efficiency. Finally, rejuvenator is only dosed on the

18 surface of RAP. The material does mingle in the conveyor belt(s), in the RAP elevator, at the

19 material transfer points (chutes) and in the RAP dryer, as well as later in the mixer. Nevertheless,

20 a less homogeneous distribution may be achieved compared to addition in the mixer. This risk is

21 higher for rejuvenators that require a small dosage rate.

\section{$22 \quad 3.2$ Rejuvenator addition at the RAP dryer outlet chute (No. 5)}

23 Rejuvenator is sprayed on the RAP material flow leaving the heating RAP dryer. The injection

24 rate can be adapted to the RAP material flow rate. 
$1 \quad 3.2 .1$ Benefits

2 The risk of rejuvenator ignition or evaporation is significantly reduced compared to rejuvenator

3 addition on RAP conveyor belt because of lower temperatures at the RAP dryer outlet as

4 compared to flame inside the RAP dryer.

5 3.2.2 Drawbacks

6 Inhomogeneous distribution of rejuvenator can occur because of spraying. This risk is decreased,

7 however, if RAP goes through the mixer afterwards.

$8 \quad 3.3$ Rejuvenator addition at the mixer (No. 8)

9 Rejuvenator is added in the mixer in a sequence to ensure direct blending with RAP before

10 addition of any virgin materials. Dosage rate is calculated based on RAP mass.

\section{3 .1 Benefits}

12 There is considerably more experience in addition of additives directly in the mixer and many

13 plants have additive dosage systems pre-installed thus virtually eliminating need for

14 modifications to the production plant. This option would also likely result in the most precise

15 dosing due to known quantity of RAP in the mixer and will result in the most homogeneous

16 distribution of rejuvenator because of mixing during the rejuvenator addition. It is possible to

17 adjust the blending time of RAP and rejuvenator as necessary.

$18 \quad$ 3.3.2 Drawbacks

19 Exposure time of RAP binder to rejuvenator is the shortest compared to previous options

20 (seconds compared to minutes, depending on plant configuration). At the same time, the

21 produced mixture is at an elevated temperature even post-production during storage, hauling, and

22 paving. This time period is considerably longer compared to the time of rejuvenator residence

23 directly on RAP binder, before addition of virgin binder and mineral aggregates. During this

24 post-production time rejuvenator diffusion into the RAP binder film continues, although at a

25 slower rate because of lower temperature and dilution in virgin binder. The diffusion will also 
1 depend on the mix composition. For example, at a very high RAP rate it would matter less if the

2 rejuvenator is added early during production process because the diffusion would continue

3 during the post-production operations while for a lower RAP rate early rejuvenator addition

4 would be of a higher importance because of rejuvenator dilution in virgin binder resulting in a

5 slower diffusion rate.

\section{4. Results of experimental production}

7 As discussed in Section 3, three locations can be analytically considered best for rejuvenator 8 addition. Two of them, No. 3 "RAP conveyor belt" and No. 8 "Mixer", were compared in a

9 practical experiment at an asphalt plant to evaluate the mixture rejuvenation effectiveness and 10 emissions during production. The third option (No.5 "RAP dryer outlet chute") can be

11 reasonably assumed to provide similar mixture performance to option No.8 "Mixer".

12 During the experiment the rejuvenator was added at two locations in the asphalt plant:

13 1) On the RAP conveyor belt (No. 3 in Figure 3). The experiment was run at RAP feed 14 rate of between 145 and $175 \mathrm{t} / \mathrm{h}$. Rejuvenator was sprayed on the RAP as illustrated in 15 Figure 4 at $3 \%$ and $5 \%$ dosage from the RAP binder mass. For mixture performance 16 testing only $5 \%$ dosage rate was used, while for emission testing both doses were tested.

17 The spray rate was adjusted by constantly monitoring RAP flow rate of the conveyor belt 18 based on pre-determined 3.9\% RAP binder content.

19 2) In the mixer (No. 8 in Figure 3). Rejuvenator was added in the $3 t$ capacity mixer by spraying it through additive addition system at 5\% dosage from the RAP binder mass.

21 The material was mixed for 120 seconds. 

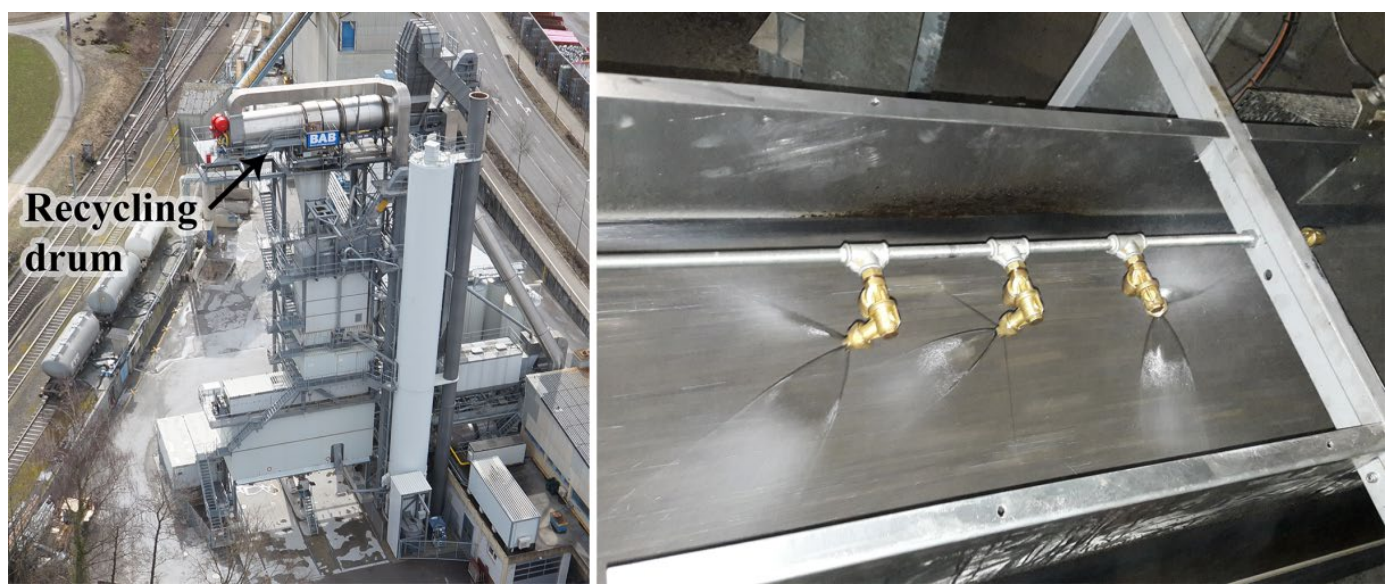

Figure 4. RAP dryer location in asphalt plant and rejuvenator spraying nozzles on cold RAP

conveyor belt

\section{$4 \quad 4.1$ Sampling}

5 The samples differ by (1) rejuvenator application location (sprayed on cold RAP on conveyor

6 belt or in mixer on hot RAP), (2) rejuvenator content (3) RAP rate. The sample abbreviation is

7 chosen to reflect these three variables (an example):

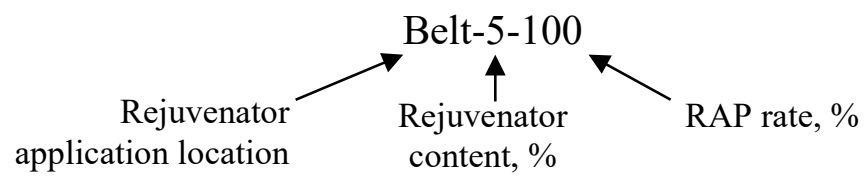

9 All the different samples considered in the research are summarized in Table 3. Three mixture

10 samples were collected for mechanical tests. In all cases the RAP passed through RAP dryer and

11 hot material (around $160^{\circ} \mathrm{C}$ ) was collected after discharge from the hot storage silos. Sampling

12 was done immediately after mixing. The samples were always collected after the previous

13 materials were cleared from the production system and the new setup had been running for

14 multiple batches. 
1 The emission measurements were performed in the inlet duct to the exhaust gas chimney and 5

2 different cases were tested (Table 3). Besides 5\% rejuvenator dose, also 3\% was used and

3 besides $100 \%$ RAP feed rate, also $60 \%$ feed RAP rate was used. The time intervals during

4 switching between the different production cases (transient phases) were excluded from the

5 analysis.

6 Table 3. Test matrix and sample abbreviation

\begin{tabular}{lllll}
\hline Abbreviation & $\begin{array}{l}\text { Rejuvenator application } \\
\text { location }\end{array}$ & $\begin{array}{l}\text { Rejuvenator } \\
\text { content }\end{array}$ & RAP rate & Testing \\
\hline None-0-100 & None & $0 \%$ & $100 \%$ & Mixture and emissions \\
Belt-5-100 & RAP cold feed belt & $5 \%$ & $100 \%$ & Mixture and emissions \\
Mixer-5-100 & Mixer & $5 \%$ & $100 \%$ & Mixture and emissions \\
Belt-3-100 & RAP cold feed belt & $3 \%$ & $100 \%$ & Emissions \\
None-0-60 & None & $0 \%$ & $60 \%$ & Emissions \\
\hline
\end{tabular}

\section{$8 \quad 4.2$ Bitumen test results}

9 As described earlier, the rejuvenator dosage of 5\% from binder mass was calculated based on

10 binder content of $3.9 \%$ that was determined before production. Test results of the produced

11 asphalt, however, demonstrate $0.5 \%$ range in the actual binder content within the gathered

12 samples. This can be attributed to the variability of reclaimed asphalt. Such range can be

13 considered acceptable since many mix design specifications allow $0.5 \%$ binder content

14 variability for virgin mixtures. Due to the fact that rejuvenator dosage was kept constant with

15 respect to RAP flow rate (Belt-5-100 sample) or RAP mass (Mixer-5-100 sample) throughout the

16 production process while the binder content of RAP varies, the rejuvenator content from binder

17 mass also varies slightly. The total binder content consists of RAP binder and rejuvenator. Since

18 the rejuvenator dosage and total binder content are known, the proportion of rejuvenator from

19 RAP binder mass can be back-calculated. These results are summarized in Table 4. Penetration 
1 test results indicate that the binder has been softened by the addition of rejuvenator in both cases

2 to a similar level. This is despite the fact that rejuvenator dosage in the Belt-5-100 sample is

3 slightly higher compared to the Mixer-5-100. It might indicate some rejuvenator loss in the RAP

4 dryer. However, an earlier study by the authors [11] indicated that rejuvenator is not lost in the

5 dryer and since the differences in test results in Table 4 are relatively small, this it might simply

6 be a sampling error or test variability.

$7 \quad$ Table 4. Bitumen empirical test results

\begin{tabular}{lllll}
\hline Sample & $\begin{array}{l}\text { Total binder } \\
\text { content, } \%\end{array}$ & $\begin{array}{l}\text { Back-calculated RAP } \\
\text { binder content, } \%\end{array}$ & $\begin{array}{l}\text { Back-calculated } \\
\text { rejuvenator dosage, } \% \\
\text { from RAP binder mass }\end{array}$ & $\begin{array}{l}\text { Penetration, } \\
0.1 \mathrm{~mm}\end{array}$ \\
\hline None-0-100 & 4.4 & 4.4 & $0.0 \%$ & 20 \\
Belt-5-100 & 4.0 & 3.8 & $5.1 \%$ & 30 \\
Mixer-5-100 & 4.5 & 4.3 & $4.5 \%$ & 33 \\
\hline
\end{tabular}

8

$9 \quad 4.3$ Stiffness

10 Complex modulus master curves of the three samples are illustrated in Figure 5. Each data point

11 is an average of four replicates. As expected due to no added rejuvenator the None-0-100 sample

12 has the highest $\mathrm{G}^{*}$ throughout the entire frequency range. Both rejuvenated samples are

13 relatively close and the Belt-5-100 has slightly higher complex modulus. Based on previous

14 reported studies [20-23], complex modulus test results are highly sensitive to binder content. It is

15 therefore possible that the difference in modulus between the Belt-5-100 and the Mixer-5-100

16 can be attributed to $0.5 \%$ binder content difference (Table 4 ). A significant difference between

17 the samples in the low frequency (high temperature) and high frequency (low temperature) range

18 can not be seen. 


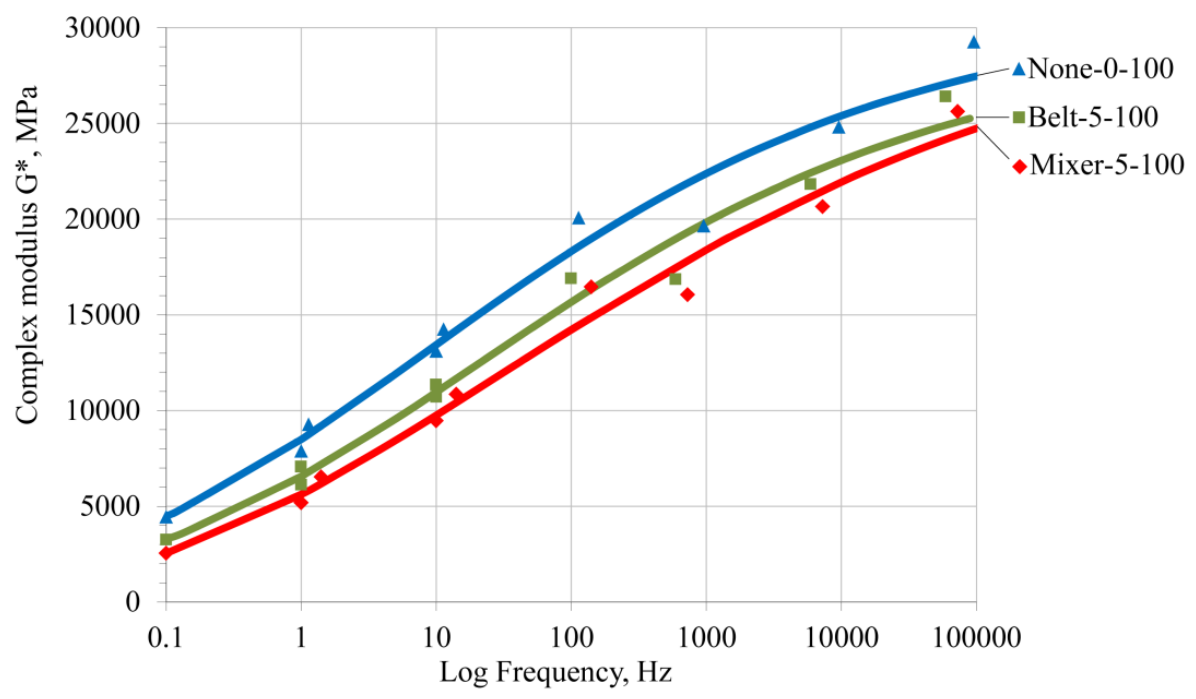

Figure 5. Complex modulus master curves (lines) and data points (markers) shifted to $20^{\circ} \mathrm{C}$

\section{$3 \quad 4.4$ Fatigue}

4 Relationship between fatigue criteria $\mathrm{N}_{\mathrm{f} / 50}$ and applied strain amplitude $\varepsilon$ is demonstrated in

5 Figure 6. Wöhler type linear regression between decimal logarithms of $\mathrm{N}_{\mathrm{f} / 50}$ and $\varepsilon$ were used to

6 obtain the necessary parameters for calculation of $\varepsilon$ according to equation:

$7 \log \left(\mathrm{N}_{\mathrm{f}}\right)=\mathrm{a}+(1 / \mathrm{b}) \times \log (\varepsilon)$, where $\varepsilon$ is the amplitude of tensile strain at cycle $100, \mathrm{~N}_{\mathrm{f}}$ is the number

8 of applications to failure, $\mathrm{a}$ is the ordinate of the fatigue line and $1 / \mathrm{b}$ is the slope. The calculated

9 parameters of tested samples are indicated in Figure 6. Only the two samples representing final

10 asphalt mixture were tested (Belt-5-100 and Mixer-5-100). Due to the amount of available

11 material, the number of replicates was smaller than the required nine.

12 Figure 5 demonstrates that the slope of the Mixer-5-100 sample is flatter compared to Belt-5-100

13 indicating shorter fatigue life. Higher number of samples should be tested to determine the

14 statistical significance of the $40 \%$ difference in strain amplitude (95\%o versus $134 \%$ ). The

15 authors are aware that the number of samples has an effect on the final results but Figure 6 is 
1 used as an indication of the fatigue performance of the mixtures. Due to the relatively high $\mathrm{R}^{2}$

2 values, it is possible that the overall trend would hold.

4 Figure 6. Fatigue diagram of Belt-5-100 and Mixer-5-100 samples showing failure criteria $N_{f / 50}$

11 displacement curves demonstrate that the characteristics of the maximum load and crack

12 propagation dynamics of the rejuvenated mixtures are also similar. Both rejuvenator addition

13 locations made the mixture less brittle as indicated by the roundness of the load-displacement

14 diagram in Figure $7 \mathrm{~b}$ in comparison to the sharp brittle failure of the non-rejuvenated mixture.

15 The FI test is highly sensitive to binder content, which is one of the reasons the test was chosen

16 for the study. From the authors' experience, testing AC8 type mixtures, $0.5 \%$ binder difference 
1 that is evident in this study can lead to increase of FI by 3 to 5 and fracture energy increase by

2 more than $600 \mathrm{~N} / \mathrm{m}$. It is therefore likely that if Belt-5-100 and Mixer-5-100 samples would have

3 the same binder content, the FI and fracture energy of Belt-5-100 would be higher compared to

4 the Mixer-5-100. In other words, early addition of rejuvenator has ensured similar active binder

5 content of the Belt-5-100 mixture compared to the Mixer-5-100, despite having lower actual

6 binder content.

7 Overall FI of all the mixtures is relatively low compared to other studies [16], and indicate crack-

8 prone mixture. However, optimization of mix design was out of the scope of the study and only

9 relative comparison between the samples is important for reaching the research objective.
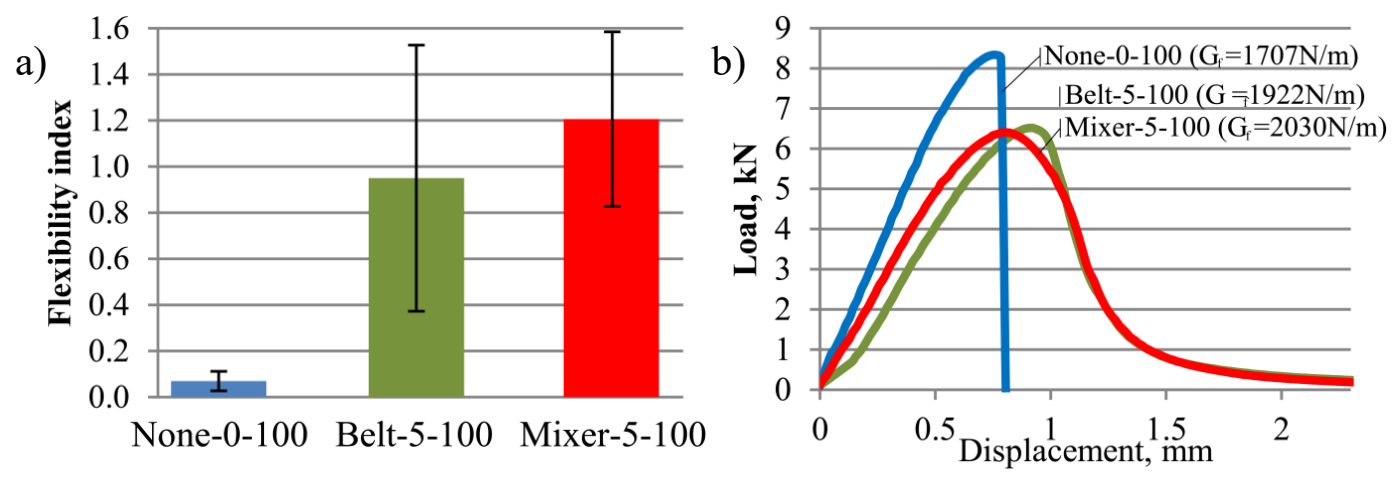

Figure 7. Flexibility index (a) and load-displacement curves (b)

\section{$12 \quad 4.6$ Emission test results}

13 Addition of rejuvenator upstream of RAP dryer holds a potential risk of its volatilization due to

14 the exposure to the extreme temperature in the dryer. It was therefore determined during the

15 experimental production if rejuvenator addition location or dosage affects the measured plant

16 emissions and the results were compared to those of conventional asphalt production. Moreover,

17 an increase in measured emissions would indicate loss of rejuvenator mass and therefore

18 reduction in its effectiveness. 
1 The experimental production was carried out in six windows by ensuring a sufficient time to

2 gather representative emissions measurements for each production case. In addition to the $100 \%$

3 RAP mixtures that were used for testing of mixture properties, $60 \%$ RAP mixture (None-0-60)

4 was produced. The None-0-60 mixture was chosen as the reference because it is within the

5 locally permitted RAP rate and thus provides a reasonable baseline. The mixture composition

6 and time of production windows according to the sequence of production are summarized in

7 Figure 8 . The average temperature during the testing day was $23^{\circ} \mathrm{C}$ with no precipitation

8 ensuring favorable ambient conditions for the measurements.

9 The emission test results and production temperature are summarized in Figure 8 following the

10 sequence of production. First of all, it is important to recognize that heating temperature is a

11 significant contributor towards generating emissions. In order to minimize the variables, every

12 effort was placed to achieve constant temperature throughout the six production windows. It can

13 be seen in Figure 8 that this was achieved since RAP material temperatures are in a narrow 160

$14{ }^{\circ} \mathrm{C}$ to $167^{\circ} \mathrm{C}$ range for all evaluation windows. For this reason RAP material temperature

15 influence on TOC emissions can be assumed to be negligible and will not be considered in

16 further analysis. 


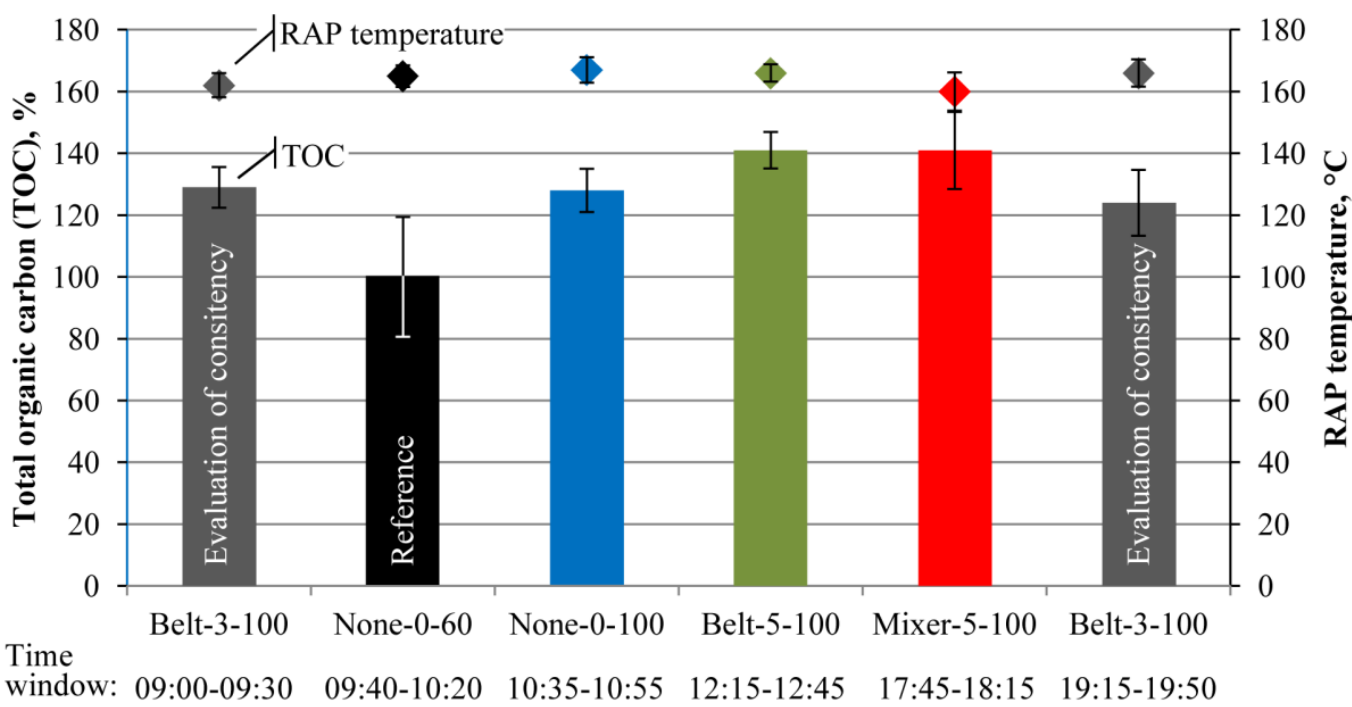

Figure 8. Total organic carbon (bars on primary axes) and RAP temperature (rhombs on secondary axes) test results (average result of each measurement time window)

4 As mentioned earlier, the None-0-60 mixture (60\% RAP) is used as the TOC emission reference.

5 All other TOC emission values in Figure 8 are normalized relative to this reference. The

6 following findings can be drawn by analyzing the TOC emissions in the figure:

7 1. Two production windows of the Belt-3-100 in the morning and evening were used to evaluate

112 . The different windows with various contents of rejuvenator at $100 \%$ RAP rate can be used to 12 evaluate the effect of rejuvenator on TOC emissions. It can be seen that compared to the $0 \%$ 13 rejuvenator window (None-0-100), the TOC emissions at $3 \%$ and $5 \%$ rejuvenator windows 14 vary slightly but, considering the test variability, they can be considered similar. Therefore, 15 based on the limited production data in this experiment, no clear correlation between TOC 16 emissions and rejuvenator addition rate can be stated. 
1 3. Comparison of the Belt-5-100 and the Mixer-5-100 windows allows evaluating the effect of

2 rejuvenator addition location on TOC emissions. It can be seen in Figure 8 that the emissions

3 in both cases are identical, indicating that there is no difference in TOC emissions whether

$45 \%$ rejuvenator is sprayed on the cold RAP on the belt or on the hot RAP directly into the

5 mixer.

64 . Since there is no significant effect of either rejuvenator addition location or rejuvenator

7 content, the $100 \%$ RAP production windows can be compared to the reference $60 \%$ RAP

8 window (None-0-60). On the average 100\% RAP samples resulted in 33\% higher TOC

9 emissions compared to the $60 \%$ RAP window. Higher TOC emissions are a common and

10 known effect when increasing the RAP rate. Generally the main contributors for this are:

11 fumes from heating RAP bitumen, RAP material grading, RAP bitumen type and content,

12 moisture content, fumes from fresh bitumen.

13 It must be noted that the above results and findings are based on and only valid for:

14 - The present one-day measurement campaign with a limited number - a total of six

15 production and evaluation windows - during the test.

16 - The particular plant type, process and design.

17 - The plant operating conditions during the test.

18 - The material properties - and in particular the RAP material properties - during the test.

$19-$ The specific rejuvenator used during the test.

20 Results may vary significantly if one or more of the above mentioned parameters are changed.

\section{5. Summary}

22 In order to summarize analytical results of the ten rejuvenator addition locations (Section 3) and

23 the experimental test results (Section 4), Table 5 was developed. Here the different rejuvenator 
1 addition options are grouped in categories of environmental effect, plant operations and resulting

2 asphalt mixture quality. Each of these categories has several parameters that are compared

3 among the different options using an arbitrary four level system as summarized in the legend. If

4 any of the parameters is rated unacceptable, this option is not evaluated further because

5 rejuvenation addition is not advised at this location. As discussed in Section 3, addition of

6 rejuvenator on RAP shredder belt (option No.1 in Figure 3) at RAP storage (No.2) or RAP inlet

7 (No.4) present environmental hazards as well as rise concerns about the rejuvenation quality.

8 Rejuvenator addition at the RAP scale (No.6), or RAP chute (No.7) will likely not ensure

9 homogeneous rejuvenator distribution. Finally, rejuvenator addition at the bitumen line/scale

10 (No.9) or in a separate bitumen tank (No.10) may not ensure sufficient rejuvenator diffusion into

11 RAP binder, potentially resulting in inferior performance. This leaves rejuvenator addition

12 options on RAP conveyor belt (No.3), RAP dryer outlet chute (No.5) and Mixer (No.8) as the

13 best choices. It must be noted that depending on the plant setup, production conditions, and

14 rejuvenator type the ranking may change. Further advances in production technology or

15 experience will also affect the ranking and possibly allow considering some rejuvenator addition

16 options that are rated unsuitable currently. Finally, the reader based on his experience and

17 external requirements may apply different weights to the various categories which will affect the

18 relative comparison of rejuvenator addition locations.

19 In the environment category application of rejuvenator in the mixer (No.8) provides somewhat

20 less operational health and safety hazards compared to the other two options (No.3 and No.5),

21 because rejuvenator is sprayed in an enclosed environment. The application on conveyor belt

22 may be prone to negative effects from weather (wind, rain) thus exposing the workers to the

23 product. This can be avoided by covering the conveyor belt and/or dosing point. The emissions,

24 as concluded by this study do are not increased as a result of rejuvenator addition. For addition 
1 upstream of RAP dryer, the rejuvenator has to be non-flammable and should not produce excess

2 emissions due to the high temperature present in the RAP dryer.

3 In the plant operation category rejuvenator addition in mixer (No.8) receives the highest

4 rating. This is because usually additive dosing system is already present in modern asphalt

5 plants, thus the addition of rejuvenator does not require additional plant modification. For the

6 other two options (No.3 and No.5), the integration of dosing system is relatively simple and well

7 worth the effort if advantages in mix performance are found. In either case rejuvenator dosage

8 can be changed flexibly based on RAP mass or flow rate.

9 In the quality category rejuvenator addition in mixer (No.8) is preferred because it ensures the

10 highest accuracy due to known RAP weight in the mixer. Other options (No.3 and No.5) have to

11 rely on flow rate or scale of cold feed belt which is not as accurate. This advantage, however,

12 should not be over-valued because rejuvenator content is based on the RAP binder content,

13 which is not consistent due to inherent RAP variability (also evident in the experimental part of

14 this study). Therefore, the accuracy of rejuvenator addition depends not only on the

15 technological processes during production but also on RAP management to ensure homogeneity

16 and quality control procedures to provide representative binder content of selected binder

17 stockpile. Homogeneous rejuvenator distribution is another concern and in this category the best

18 results can be ensured in the mixer, while for other options a somewhat less homogeneous

19 distribution is possible, especially if low rejuvenator dosage is used. Nevertheless, good

20 distribution can be reasonably expected also when dosing the rejuvenator before mixer, because

21 of agitation during the production process as well as eventually blending in the mixer. Finally,

22 the test results of this study demonstrate that there might be an advantage to add rejuvenator on

23 the RAP conveyor belt (No.3) to ensure higher fatigue and crack propagation resistance which 
1 are the key pavement distress concerns when using high RAP rate. This option therefore receives

2 the highest rating in the mix performance category because it allows the rejuvenator to come in

3 contact with the RAP binder directly and interact with it for a longer time compared to the other

4 two acceptable locations. Rejuvenator addition in mixer, however, has been proven as a

5 successful ongoing practice in many asphalt plants and therefore receives rating "good

6 performance".

7 Table 5. Comparison of potential rejuvenator addition locations

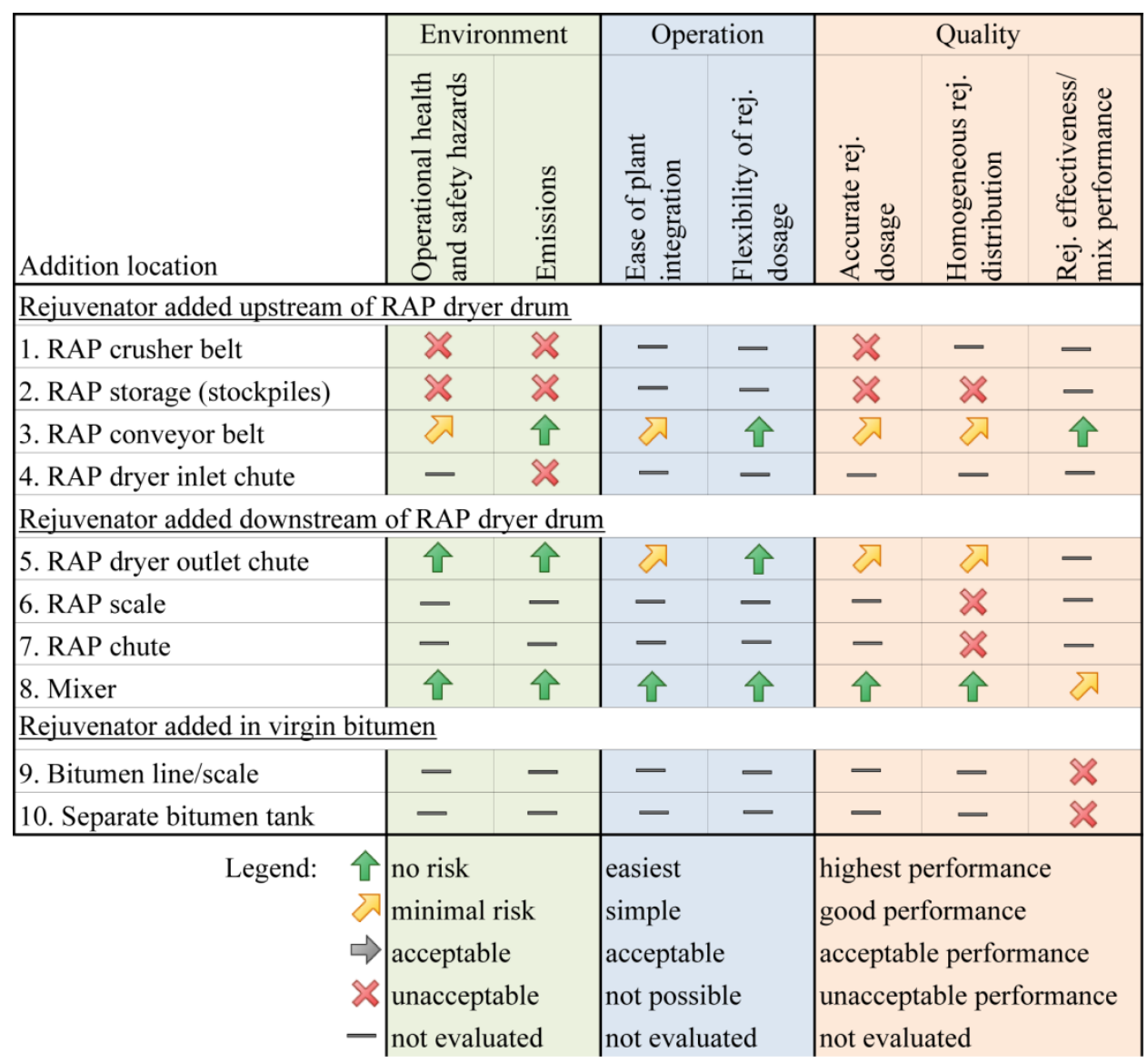

\section{6. Conclusions}

10 With ever increasing reclaimed asphalt content in asphalt mixtures, rejuvenator use is becoming

11 inevitable for ensuring the required pavement performance. This research evaluated the possible 
1 rejuvenator addition locations in one type of asphalt plant in order to provide guidelines to

2 benefits and drawbacks for each of them. Although the work is done for batch type asphalt plant,

3 the rationale behind the analysis can be applied to any type of asphalt mixing plant. In total ten

4 locations were identified and analyzed analytically and two most promising were chosen for

5 further investigation. The results were compared in a practical experiment as summarized in a

6 Video 1 (https://youtu.be/LYBq93e8BG0). RAP was heated to $160^{\circ} \mathrm{C}$ in counter flow heating

7 RAP dryer and a rejuvenator was applied to cold RAP on feed belt and to hot RAP in mixer.

8 Three asphalt mixture samples were gathered to evaluate the effect of rejuvenator addition

9 location on binder properties and asphalt mixture mechanic performance. Emissions were

10 measured during the production to determine the environmental effects of rejuvenator addition

11 location and high RAP use in general. Based on the test results and analytical assessment, the

12 following conclusions can be made:

$13-$ From the ten possible locations rejuvenator addition to reclaimed asphalt on conveyor

14 belt, dryer outlet chute or plant mixer are recommended.

$15-$ Rejuvenator addition on cold RAP on conveyor belt provided the same crack propagation

16 resistance as rejuvenator addition on hot RAP in mixer despite $0.5 \%$ lower binder

17 content.

$18-$ Rejuvenator addition on cold RAP conveyor belt provided higher fatigue resistance

19 compared to addition in hot mixer (the fatigue tests did not have enough repetitions to

20 conform to standard).

$21-$ The samples for which rejuvenator was applied in mixer had lower complex modulus.

22 This however, might be due to the $0.5 \%$ higher binder content compared to the samples

23 where rejuvenator was sprayed on the reclaimed asphalt conveyor belt. 
- Rejuvenator addition resulted in no significant TOC emission increase, irrespective of 3\% or $5 \%$ rejuvenator addition compared to $0 \%$ rejuvenator addition. conveyor belt on cold RAP or into the mixer on hot RAP. - Increase in RAP rate also increased TOC emissions - a common and known effect.

The future work includes determining the long term diffusion of rejuvenator, including aging of

7 the samples. Different asphalt plant configurations with lower RAP contents should also be tested and other rejuvenator types should be validated. Finally, a rejuvenator addition procedure

9 in the laboratory should be established to simulate a given scenario in the asphalt plant.

\section{Acknowledgements}

11 This work was supported by Swiss federal office for the environment (BAFU) grant No.

12 UTF489.19.14/IDM for a project titled "Sustainable Fully Recycled Asphalt Concrete".

\section{References}

[1] W. Mogawer, T. Bennert, J.S. Daniel, R. Bonaquist, A. Austerman, A. Booshehrian, Performance characteristics of plant produced high RAP mixtures, Road Mater. Pavement Des. 13 (2012) 183-208. doi:10.1080/14680629.2012.657070.

[2] R. West, D. Timm, R. Willis, B. Powell, N. Tran, D. Watson, M. Sakhaeifar, R. Brown, M. Robbins, A. Vargas-Nordcbeck, F.L. Villacorta, X. Guo, J. Nelson, Phase IV NCAT pevement test track findings, 2012. M. Zaumanis, R.B. Mallick, R. Frank, 100\% Hot Mix Asphalt Recycling: Challenges and Benefits, in: Transp. Res. Procedia, 2016: pp. 3493 - 3502. doi:10.1016/j.trpro.2016.05.315.

[4] M. Makowska, K. Aromaa, T. Pellinen, The rheological transformation of bitumen during the recycling of repetitively aged asphalt pavement, Road Mater. Pavement Des. 18 (2017) 50-65. doi:10.1080/14680629.2017.1304266.

[5] M. Dinis-Almeida, J. Castro-Gomes, C. Sangiorgi, S.E. Zoorob, M.L. Afonso, Performance of Warm Mix Recycled Asphalt containing up to 100\% RAP, Constr. Build. Mater. 112 (2016) 1-6. doi:10.1016/J.CONBUILDMAT.2016.02.108.

[6] M.C. Cavalli, M.N. Partl, L.D. Poulikakos, Measuring the binder film residues on black rock in mixtures with high amounts of reclaimed asphalt, J. Clean. Prod. 149 (2017) 665-672. doi:10.1016/j.jclepro.2017.02.055.

[7] P. Shirodkar, Y. Mehta, A. Nolan, K. Sonpal, A. Norton, C. Tomlinson, E. Dubois, P. Sullivan, R. Sauber, A study to determine the degree of partial blending of reclaimed asphalt pavement (RAP) binder for high RAP hot mix asphalt, Constr. Build. Mater. 25 (2011) 150-155. doi:10.1016/J.CONBUILDMAT.2010.06.045.

[8] B. Huang, G. Li, D. Vukosavljevic, X. Shu, B.K. Egan, Laboratory investigation of mixing hot-mix aspahlt with reclaimed asphalt pavement, Transp. Res. Rec. J. Transp. Res. Board. (2005) 37-45.

35 [9] T. Bennert, R. Dongree, Backcalculation method to determine effective asphalt binder properties of recycled 

09 .

[10] D. Lo Presti, A. Jiménez del Barco Carrión, G. Airey, E. Hajj, Towards 100\% recycling of reclaimed asphalt in road surface courses: binder design methodology and case studies, J. Clean. Prod. 131 (2016) 43-51. doi:10.1016/j.jclepro.2016.05.093.

[11] M. Zaumanis, M.C. Cavalli, L.D. Poulikakos, Effect of rejuvenator addition location in plant on mechanical and chemical properties of RAP binder, Int. J. Pavement Eng. (2018). doi:10.1080/10298436.2018.1492133.

[12] M.C. Cavalli, M. Zaumanis, E. Mazza, M.N. Partl, L.D. Poulikakos, Effect of ageing on the mechanical and chemical properties of binder from RAP treated with bio-based rejuvenators, Compos. Part B Eng. 141 (2018). doi:10.1016/j.compositesb.2017.12.060.

[13] M. Zaumanis, R.B. Mallick, R. Frank, 100\% recycled hot mix asphalt: A review and analysis, Resour. Conserv. Recycl. 92 (2014). doi:10.1016/j.resconrec.2014.07.007.

[14] M. Witczak, O. Fonseca, Revised Predictive Model for Dynamic (Complex) Modulus of Asphalt Mixtures, Transp. Res. Rec. J. Transp. Res. Board. 1540 (1996) 15-23. doi:10.3141/1540-03.

[15] M.L. Williams, R.F. Landel, J.D. Ferry, The Temperature Dependence of Relaxation Mechanisms in Amorphous Polymers and Other Glass-forming Liquids, J. Am. Chem. Soc. 77 (1955) 3701-3707.

[16] H. Ozer, I.L. Al-Qadi, J. Lambros, A. El-Khatib, P. Singhvi, B. Doll, Development of the fracture-based flexibility index for asphalt concrete cracking potential using modified semi-circular bending test parameters, Constr. Build. Mater. 115 (2016) 390-401.

[17] E. Colery, S.S. Haddadi, S. Sreedhar, S. Lewis, Y. Zhang, B. Wruck, Binder grade bumping and high binder content to imporve performance of RAP-RAS mixtures, Corvallis, OR, 2018. http://www.oregon.gov/ODOT/Programs/ResearchDocuments/SPR797_Binder-GradingBumping.pdf.

[18] M. Zaumanis, A. Valters, Comparison of two low-temperature cracking tests for use in performance-based asphalt mixture design, Int. J. Pavement Eng. In press (2019).

[19] L. Boesiger, M. Zaumanis, L.D. Poulikakos, M.C. Cavalli, R. Fierz, B. Kunz, Assessment of Rejuvenator Addition in Asphalt Plants, in: Poster Present. EATA 2017 Conf., Zurich, Switzerland, 2017.

[20] J.B. Sousa, J.C. Pais, M. Prates, R. Barros, P. Langlois, M.-M. Leclerc, Effect of aggregate gradation on fatigue life of asphalt concrete mixes, Transp. Res. Rec. 1630 (1998) 62-68.

[21] G.W. Maupin, B.K. Diefenderfer, Design of a high-binder high-modulus asphalt mixture, Virginia Transportation Research Council, Richmond, VA, 2006.

[22] W.A. Zeiada, K.E. Kaloush, B.S. Underwood, M.E. Mamlouk, Improved method of considering air void and asphalt content changes on long-term performance of asphalt concrete pavements, Int. J. Pavement Eng. 15 (2014) 718-730. doi:10.1080/10298436.2013.857775.

[23] M. Zaumanis, L.D. Poulikakos, M.N. Partl, Performance-based design of asphalt mixtures and review of key parameters, Mater. Des. 141 (2018) 185-201. doi:10.1016/j.matdes.2017.12.035. 